\title{
Effect of Ambient Illumination, Screen Resolution and Zoom Level on Performance of Typing on Computers
}

\author{
Khamaj A. ${ }^{1}$, Ameer A. K. ${ }^{2}$, Samy A. M. ${ }^{2}$ \\ ${ }^{1}$ Dept. of Industrial Engineering, College of Engineering, Jazan University, jazan, Saudi Arabia \\ ${ }^{2}$ Dept. of Production Engineering and mechanical Design, Faculty of Engineering, Mini University, Egypt \\ Corresponding author:abdelhalim196@hotmail.com
}

Article History: Received: 10 November 2020; Revised 12 January 2021 Accepted: 27 January 2021; Published online: 5 April 2021

\section{$\underline{\text { ABSTRACT }}$}

Objective: This work aims to investigate effect of the ambient illumination, screen resolution and Zoom levels on visual-related task performance. The job used in this research is typing on computers. Speed of typing paragraph and typing quality were defined as the task performance.

Background: In recent years, computers play a remarkable role in nearly everyone's daily life. We use computers for various purposes and under a wide range of ambient illumination. High illumination level usually results in some problems. Adjusting screen resolution and zoom level are common solutions contra problems for visibility due to unsuitable illuminations.

Method: Ambient illuminations were examined 114, 230, 340, 420 and 520 1x. Screen resolution scales were diverse to cover all range of regulate ability pliable by characteristics of the offering used; $768 * 1024,720 * 1280$ and $768 * 1366$. Zoom levels was tested 50, 100, 150 and $200 \%$.

Results: Based on this study, can be found that, the more effective illumination level on average typing time was 340 followed by $420 \mathrm{~lx}$. Average typing time decrease with increasing screen resolution, the minimum average typing time observed at $720 * 1280$ and $168 * 1366$ screen resolution. Change the zoom level of text show significant effect on typing time, which the average typing time decreases with increasing zoom level. The minimum typing time observed at 100 and $150 \%$ zoom level. Experimental results for all S/N ratio, mean, and standard deviation (real) response values show that, illumination level, screen resolution and zoom scale are the significant parameters among all controllable factors that influence the avearge typing time. Based on $\mathrm{S} / \mathrm{N}$ Ratio the optimum parameters was $114 \mathrm{~lx}$ illumination level and $768 * 1024$ screen Resolution and 50\% zoom level. Based on standard deviation the optimum parameters was 114 lx illumination level and $768 * 1366$ screen Resolution and $150 \%$ zoom level. Based on the means the optimum parameters was is 230lx illumination level and 768*1366 screen Resolution and 100\% zoom level. 
Conclusion: The provision of suitable illumination, screen resolution and zoom levels that feedback to enhancing the performance of typing performance on computers.

Application: This study can inform in-computer typing offices and policy makers concerned with human factors and work-study.

\section{KEYWORDS:}

Illumination, Screen resolution, typing time, computers, Zoom scale

\section{INTRODUCTION}

Computer has been playing a significant role for various activities in our daily lives. There is a common usage of computer in both workplaces and offices. With this heavy employment, computer is establishes to work under an enormous range of many ambient illuminations scale. For example, accuracy work like product monitoring in storehouse requires approximately 200 lx light level. Precision work such as working in the lodge requires around 400 1x. The more accuracy is required in work efficiency, the higher ambient illumination will be necessary. The recommended illumination by Thai citizen organization [1] is $1600 \mathrm{~lx}$ for the towering accuracy job level such as one include measurement of nearly small parts.

The suggested illumination standard for ideal office activities is in between of 200-750 lx [2]. The main purpose for giving guidelines for the use of ambient illumination is due to the fact that this factor may largely affect a humans working performance as well as health concerning number (e.g., headache, eye distress), and blur visibility [3]. Past research has shown that both consistency and color of the light bulb affect percentage of right response in character correspondence [4]. This particular test was make at 250, 500, 1000 and 2000 lx. reminder that though 2000 lx is theorize beyond illumination track, it can be generally found in various areas that as steel and copper inscription mission in whose computer or different types of visual shows are yet in employ [5]. This high scale of ambient illumination leads to other visual problem, detraction in contrast between objective and its background.

Working at under high illumination scale, would lead to problem with glow is rather collective. For example, using computer outside on a sunlit day, the sunlight could promptly shine down on the computer screen. This status results in direct glow within observer's visual field. On the other hand, light may bring reflected from something's (e.g. doors, windows, walls, side mirror of the car, partitions) and finally boost the total illumination scale leading to glow in the similar way. The final case is known as reflected glow situation. When working with visual display station, issues with glow may also arrive in reflection compose. Computer users can facilely experiment light striking onto the presentation and finally leads to squeaky reflections of the surroundings superimpose on the to-be-visible data. These reflections can distract the supervisor's eyes due to its rising brightness and lowering contrast in the midst the data and its background, [6].

One way to cope with glow generated from rising luminance surrounding is to set screen brightness to identify with the surrounding luminance scale (also known as luminance ratio). Digital displays have made it plain to display text in spot color and contrast groups. In 
combination with advanced understand and calculate capabilities, the form of the display can be rapidly transmit based upon the essential characteristics of the meaning, status conditions, or even understand characteristics of a interviewer, [7]. Unfavorable or "reverse" polarity show so named because they utilize light text on a blackish background, as dissenting to black-onwhite positive polarity shows have been in concerted use since the days of microfiche perusal devices, [8] and have more lately become bronchially in mobile and automotive interfaces. In the automotive section, such offering are surpass because the blackish background of the supine polarity show lacing wear and tear on the screen, medley in with the domestic of the car, and reduces ambient illumination in the cabin through nighttime driving (i. e., positive polarity shows may enunciate more light in the cabin and growing glow). In some production implementation, changes in the polarity of the showed are made in restraint to ambient situation, however other arrangement use a supine polarity show at all times. In the mobile device section, negative polarity designs are less controlling, and their use show to be more aesthetically encourage, or are used in echo to the understand optimization of the offer for ambient illumination. As example, guidelines for development on the Apple monitor rostrum hardly promote the use of passive polarity show because the blackish background medley in with the hardware's blackish span. More mostly, passive polarity resolve popularly indicate a more "high tech" aesthetic.

Now, the explorer on the color appearance phenomenon is generally under 1000Lx [9]. Different color perception is creating by the same color in several media and environment. Nowadays, LCD show is magnetizing rising attention in daily life. With the fast development of image show technology, the sincerity transportation of color is wished for higher and higher from one instrument to another and the delicate convey of cross-media color is an emerging examine area in color banner[10]. As a case of experiment, ambient illumination is a remarkable factor simulating the image impersonation of the display. Color perception understand by human eyes under ambient illumination of outside is not the same as it under common illumination of indoor [11]. After measurement, the ambient illumination of outdoor is better to $11,000 \mathrm{Lx}$ at $10: 00$ in the sunny morning. However the current chromatic modification data, stream identical color data, and different criterion for image cloning in several profession, essentially are obtained or standardize below 1000 Lx. So there is an imperative need to examine display beneath high ambient illumination and settle the problem of color cloning of high illumination. Nowadays, the examiner of the color appearance phenomena beneath, high ambient illumination is very restricted. During 2010, Choi, Luo and Pointer discuss the variation in color appearance of a great show emerge from several illumination status (dark, indoor and outdoor). In addition, every of the approaching test colors were estimate by 10 observers employ a magnitude appreciation method [12]. Within 2013, Baek, Kwak and Park found that the monitor brightness is influenced by besetment condition and the understand brightness of each test repeater lessening when besetment ratio (SR) is higher than one contrast to that beneath dark room. The comprehend brightness amount of six test repeater with various luminance scales were estimated using magnitude evaluated technique to discuss the surround luminance impact [13]. Images showed on a screen are familiar to be discoloring by ambient illumination, including naturalistic light or theatrical illumination. Many researchers have investigating the effects of domestic illumination on the 
image quality of offering screens and proposition some results. It was propose that ambient light not only had an impact on the understand color on a screen, but furthermore effected the diagnosis on radiological images [14], performance of the correspondence[15], and the understanding for letter approaching on a screen [16-18]. Thus, ambient illumination inland is suggests troubling not only the color visibility but also the execution of apparent tasks. The performances of mobile depots such as a phone or a plaster used outdoors could be affected more roughly by powerful natural illumination as contrasted indoor illumination. Furthermore, a variation in ambient lighting could dramatically modify the perception of photo or texts showed on mobile depot screens [19]. Thence, to perceive good screen showing under different ambient illumination situations, investigators have insert the perceived image disparity reparations ratios [20] or the color aspect model for the optimized parameters [13] to offset the trouble of ambient light situation (from dark to luminous) on the display execution. However, these procedures could help people to opinion the screens comfortably, they were not ideal. Headmost, the parameters were not stationary, and various with growing ambient luminance. However, various studies assured that with growing consistency of ambient illumination, the screen backlight luminance produces was also desired to understand the display effects. Though, rising backlight luminance purposed more power consuming; thus, investigators have concentrate on finding procedures to acquire suitable screen backlight luminance by optimizing IQ and energy consuming under rising lighting conditions. Images showed on mobile terminals are impact by rising ambient illumination. This work sets out to discuss the effects of ambient illumination on photograph quality. In this research, twenty test images, which were show on a mobile phone with six scales of screen backlight luminance, were visually estimate fewer than six scales of ambient illumination up to 20,000 lx. In the visual test, many perceptual attributes inclusive brightness, contrast, and overall image quality were estimate via the conclusive referee method. The test results suggest that image quality dismiss with increasing ambient minaret, incident upon the screen. Moreover, the image quality and ambient contrast ratio ACR could be expresses by a logarithmic relevance [21]. Finally, a sample was proposes to discover the effects of the high ambient illumination on image quality based on the ambient contrast ratio. The possibility to make dye-sensitized solar cells using nontoxic and cheap materials under accustomed lab or industrial conditions, i.e. without a cleanroom, has rebellious large attention in this technology through the last decades. Dye-sensitized solar cells are knows to task well in soft light or widespread light conditions. So, they could be enjoyable for inside use, where the ambient light may have different shadow. In dye-sensitized solar cells, a pigmentation jot absorbs the visional light, [22]. The qualification is influence by the overlapping stage of the maxima in the pigmentation absorption shadow and in the illumination shadow, i.e. out of a suitable choice of pigmentation; the qualification can be maximized for each illumination situation. Illumination effects attitude, but no studies to date have provided a integrate theory that explains the seemingly antithetical findings of illumination on gregarious behaviors. We patch prior findings and studied psychosomatic and behavioral consequences of lighting, specifically centering on its belongings on prosaically behaviors such as financial endowment and volunteerism, [23]. Three studies backup our supposition. total, we explain that luminous light dilate individuals' predominant restraint to an occasion to support others inter subordinate show major foresight for others beneath luminous light and contribute more 
time and money; while independents concentrate additional on the self beneath luminous light and contribute less time and money.

This work aims to investigate effect of the ambient illumination, screen resolution and Zoom levels on visual-related task performance. The work done in this research is typing on computers. Speed of typing paragraph and typing accuracy was defined as the task performance. Ambient illuminations were investigated in 114, 230, 340, 420 and 520 1x. Screen resolution levels were varied to cover all range of adjusts ability allowed by characteristics of the show used; 768*1024, 720*1280 and 768*1366. Zoom levels was tested 50, 100, 150 and $200 \%$.

\section{METHODOLOGY}

\section{Subjects}

The number of participants to this study is twenty, all participants of male. Their age ambits are between 21 - 24 years old. All participants had no harm in the arms, wrists, and hands on each side. Participants did not wear any glasses through the study. Furthermore, participants own experience in utilize computer on a daily foundation.

\section{Experimental Setting}

Preparation used in the study include desk. The desk, dimensions were $700 \mathrm{~mm}$ height $900 \mathrm{~mm}$ width, and $2000 \mathrm{~mm}$ length. The curtain on windows was built-up in order to minimize any potential additional light agent from other light regulation outside the laboratory. A computer used in this study was laptop. Screen dimensions were 15.9 inch horizontally and 15 inch vertically. Laptop screen was located on the desk surface at $500 \mathrm{~mm}$ distance measured from the participant's eye to screen center.

Illumination level was measured by Digital Lux Meter. Participants were asked to type the provided paragraph. Typing time in seconds measured from the starting of target shown to the finishing of typing the paragraph by participant.

\section{Experimental Design.}

Freelance variables in this study contain three major parameters. First, thither were five ambient illumination scales; 114, 230, 340, 420 and 520 lux. Illumination grade was measure by Digital Lux Meter at the computer desk surface. Secondly, three screen resolution levels were tested; $768 * 1024,720 * 1280$, and 768*1366. Last of all, Zoom levels was tested 50, 100, 150 and $200 \%$. Meantime, since some letter could request lower time to gender than others, all target letters in the test were classified into three categories. The first group is characters known to lowercase. The last group is characters known to stop signs.

In addition to target characters, there were also few further observation variables. The screen color was adjusted to true color (64 bit) for all situations. The font form used was Times New Roman with sacrificial 18 point in height. Subordinate variable was the intermediate typing time per paragraph measure in second unit.

The design of experiences is $5 * 1+3 * 5+4 * 5+3 * 4 * 5$ (100 conditions) within subject design. The following tables 1- 6 have shown the total number of experiments with the different conditions. 
Table 1: the experiments should be carrying at illumination levels, screen resolution and zoom level

\begin{tabular}{|c|c|c|c|c|c|c|c|}
\hline $\begin{array}{c}\text { Illumination, } \\
5 \text { experiments }\end{array}$ & \multicolumn{3}{|c|}{ Screen Resolution, 15 experiments } & \multicolumn{3}{c|}{ Zoom level \%, 20 experiments } \\
\hline $1141 \mathrm{x}$ & $768 * 1024$ & $720 * 1280$ & $768 * 1366$ & 50 & 100 & 150 & 200 \\
\hline $2301 \mathrm{x}$ & $768 * 1024$ & $720 * 1280$ & $768 * 1366$ & 50 & 100 & 150 & 200 \\
\hline $340 \mathrm{~lx}$ & $768 * 1024$ & $720 * 1280$ & $768 * 1366$ & 50 & 100 & 150 & 200 \\
\hline $4201 \mathrm{x}$ & $768 * 1024$ & $720 * 1280$ & $768 * 1366$ & 50 & 100 & 150 & 200 \\
\hline $5201 \mathrm{x}$ & $768 * 1024$ & $720 * 1280$ & $768 * 1366$ & 50 & 100 & 150 & 200 \\
\hline
\end{tabular}

Table 2: the experiments at 114 Ix illumination levels, screen resolution and zoom level

\begin{tabular}{|c|c|c|c|c|}
\hline \multicolumn{5}{|c|}{ Illumination, 114 lx } \\
\hline Screen Resolution & \multicolumn{4}{|c|}{ Zoom level \%,12 experiment } \\
\hline $768-1024$ & 50 & 100 & 150 & 200 \\
\hline $720-1280$ & 50 & 100 & 150 & 200 \\
\hline $768-1366$ & 50 & 100 & 150 & 200 \\
\hline
\end{tabular}

Table 3: the experiments at 230 Ix illumination levels, screen resolution and zoom level

\begin{tabular}{|c|c|c|c|c|}
\hline \multicolumn{5}{|c|}{ Illumination, $230 \mathrm{~lx}$} \\
\hline Screen Resolution & \multicolumn{3}{|c|}{ Zoom level \%,12 experiment } \\
\hline $768-1024$ & 50 & 100 & 150 & 200 \\
\hline $720-1280$ & 50 & 100 & 150 & 200 \\
\hline $768-1366$ & 50 & 100 & 150 & 200 \\
\hline
\end{tabular}

Table 4: the experiments at 340 Ix illumination levels, screen resolution and zoom level

\begin{tabular}{|c|c|c|c|c|}
\hline \multicolumn{5}{|c|}{ Illumination, 340 lx } \\
\hline Screen Resolution & \multicolumn{5}{|c|}{ Zoom level \%,12 experiment } \\
\hline $768-1024$ & 50 & 100 & 150 & 200 \\
\hline $720-1280$ & 50 & 100 & 150 & 200 \\
\hline $768-1366$ & 50 & 100 & 150 & 200 \\
\hline
\end{tabular}

Table 5: the experiments at 420 Ix illumination levels, screen resolution and zoom level

\begin{tabular}{|c|c|c|c|c|}
\hline \multicolumn{5}{|c|}{ Illumination, 420 lx } \\
\hline Screen Resolution & \multicolumn{4}{|c|}{ Zoom level \%,12 experiment } \\
\hline $768-1024$ & 50 & 100 & 150 & 200 \\
\hline $720-1280$ & 50 & 100 & 150 & 200 \\
\hline $768-1366$ & 50 & 100 & 150 & 200 \\
\hline
\end{tabular}


Table 6: the experiments at 520 Ix illumination levels, screen resolution and zoom level

\begin{tabular}{|c|c|c|c|c|}
\hline \multicolumn{5}{|c|}{ Illumination, 520 lx } \\
\hline Screen Resolution & \multicolumn{4}{|c|}{ Zoom level \%,12 experiment } \\
\hline $768-1024$ & 50 & 100 & 150 & 200 \\
\hline $720-1280$ & 50 & 100 & 150 & 200 \\
\hline $768-1366$ & 50 & 100 & 150 & 200 \\
\hline
\end{tabular}

\section{Experimental Procedure}

The initial step of the testing was to calibrate devices and screen to ensure all monitoring variables. Then, the participants take a test on each situation with ten minutes break in between while completing the sixty situations. The task to be complete is typing paragraph according to work sheet. The time took the typing complete paragraph was recorded for each participant, then compute the average time from twenty participants.

\section{Test Environment}

Participants typing on laptop installed windows 10 . The data were collected for the time duration that participants completed typing the paragraph, which included also typing accuracy. The paragraph was containing 74 words with 18 point font size and Times new roman characters type. The experiments were carried out at room temperature about $23 \mathrm{C}^{\circ}$.

\section{Experimental Data Analysis}

The data analysis will be done in two steps; first step is the determination of the most important parameters affecting the response, this will be done by using the response table and main effect and interaction graphs. The second step is to determine the significance of these parameters according to their effect on the response using the ANOVA. The analysis of variance (ANOVA) and of mean (ANOM), standard deviation of the observed raw data, and S/N ratio as smallest the better are carried out to identify the significant variables and to quantify their effects on the response characteristics.

\section{RESULTS AND DESSCUSIONS}

The effect of illumination level on average typing time was shown in Fig. 1. The illuminatin level show significant effect on reduction typing time, it can be noticed that, the avarge typing time decreases with increasing illumination level. The lowest typing time observed at 340 and 420 lx. Illumination level. The average typing accuracy at different illumination levels, shown in Fig. 2. The hights accuracy observed at 340 lx illumination levels followed by 420 lx. This observition correspond the results of illumination level with average typing time. 


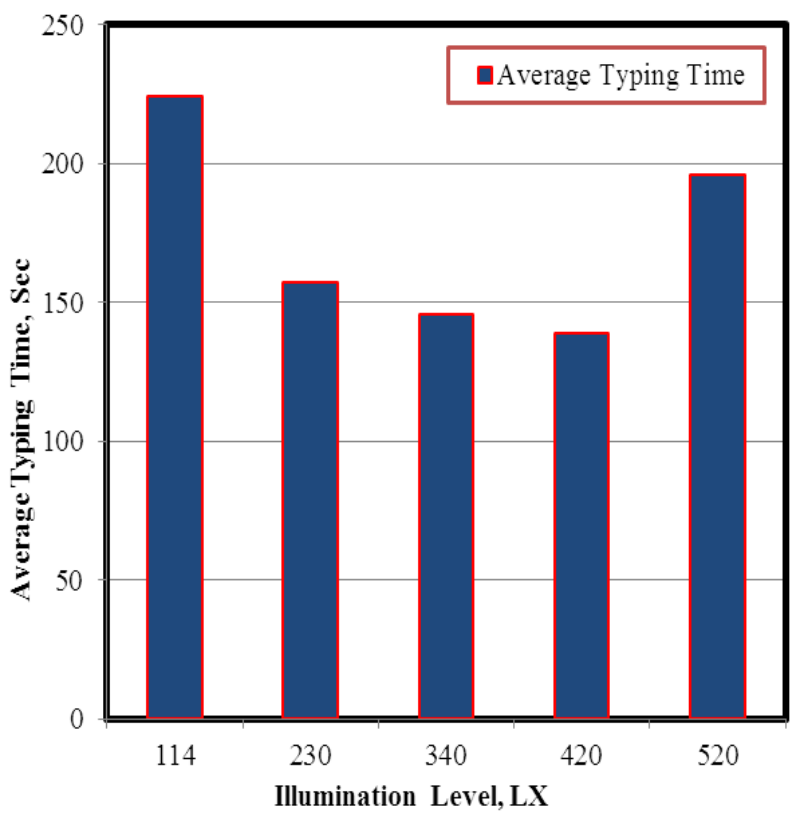

Fig. 1 main effect of illumination level on average typing time

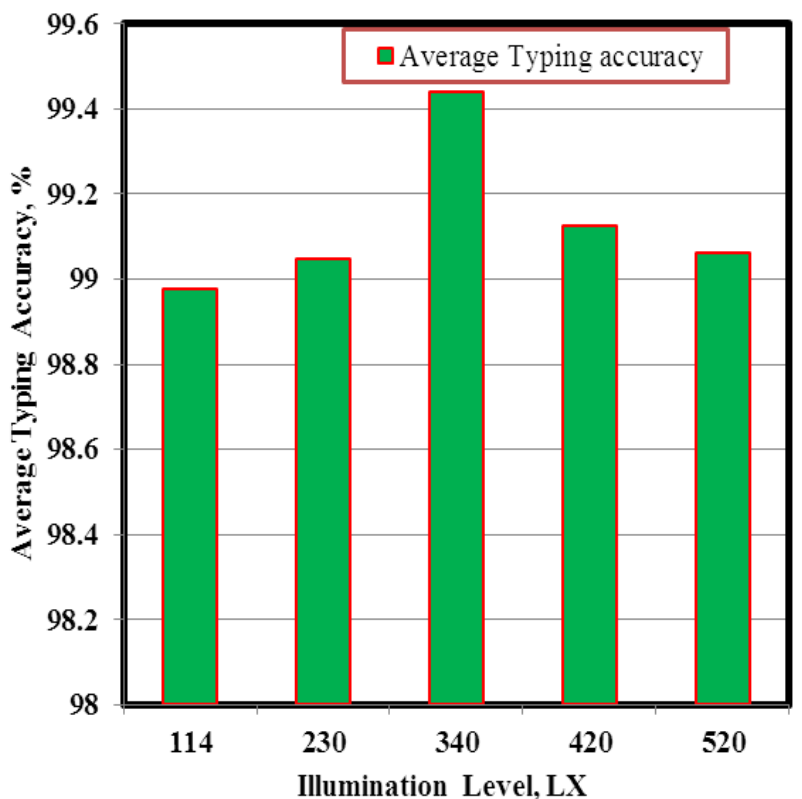

Fig. 2 main effect of illumination level on average typing accuracy

Figure 3 show the main effect of screen resolution on average typing time. It can be noticed that the average typing time decreases with increasing screen resolution up to $720 * 1280$, then slightly increase. The lowest average time was observed at screen resolution $768 * 1280$. The average typing accuracy was show in Fig. 4. The high accuracy observed at screen resolution $720 * 1280$.

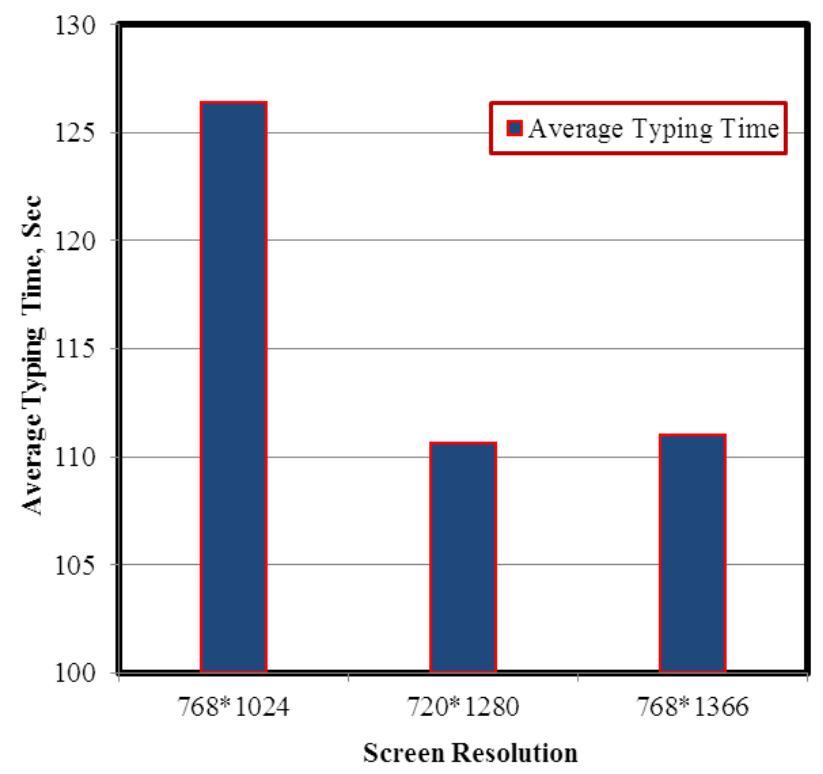

Fig. 3 main effect of screen resolution on average typing time

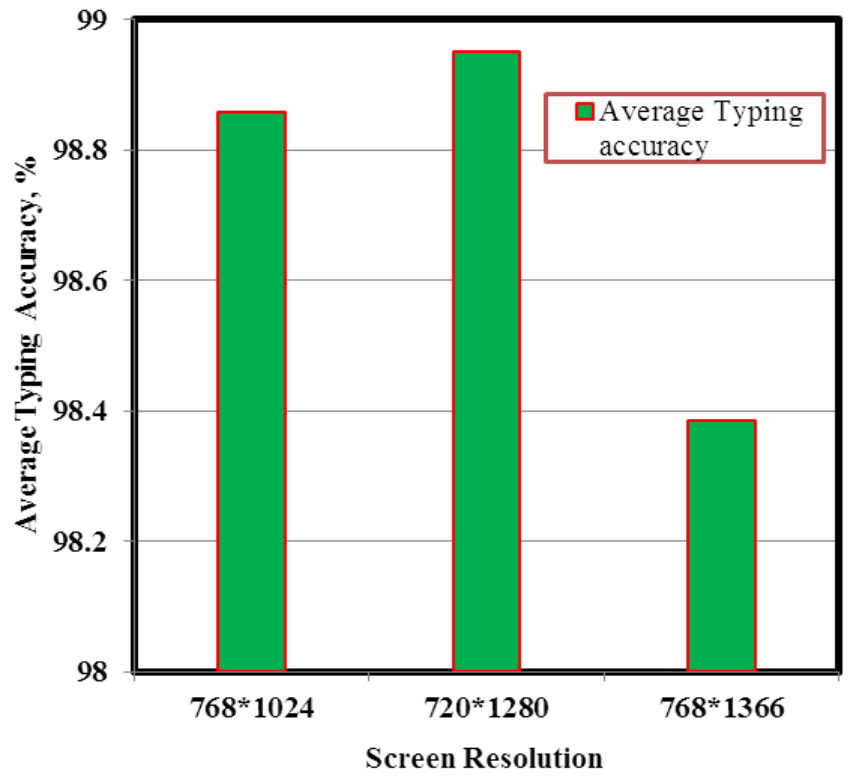

Fig. 4 main effect of screen resolution on average typing accuracy 
The main effect of Zoom level on average typing time was show in Fig. 5. The average typing time decrease with increasing zoom level up to $150 \%$, then slightly increasing at $200 \%$ zoom level. The average typing accuracy shown in Fig. 6, we can be observed the same level of typing accuracy for all zoom levels.



Fig. 5 main effect of zoom level on average typing time

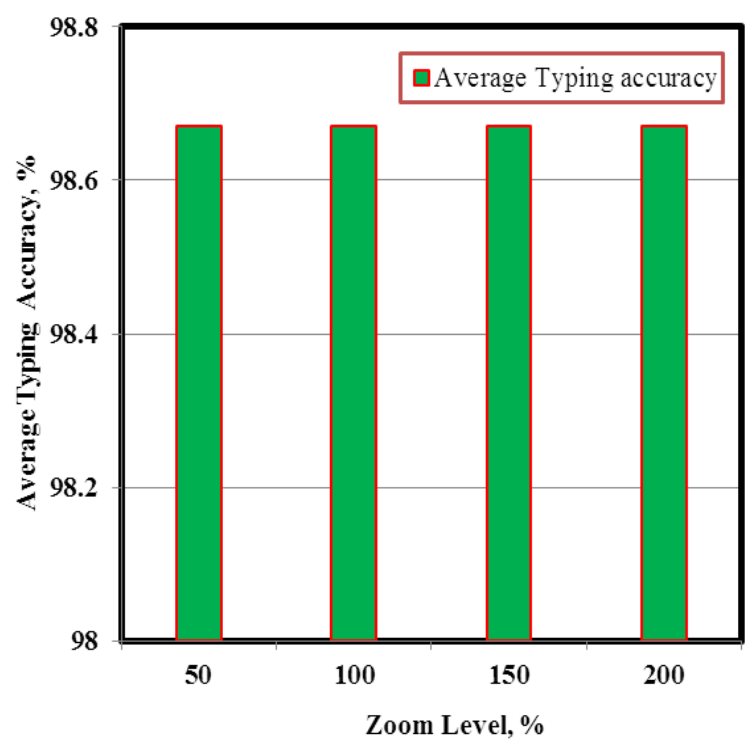

Fig. 6 main effect of zoom level on average typing accuracy

Figure 7 show the Interaction plot between illumination level and average typing time at different screen resolution, the average typing time decrease with increasing illumination level up to $340 \mathrm{~lx}$, then increase with increasing illumination level. The minimum average typing time observed at $340 \mathrm{~lx}$ illumination level. The same trend observed at all screen resolution. The minimum values of typing accuracy observed at all screen resolution and 340-illumination level. Figure 8. Show the Interaction plot between illumination level and average typing accuracy at different screen resolution.

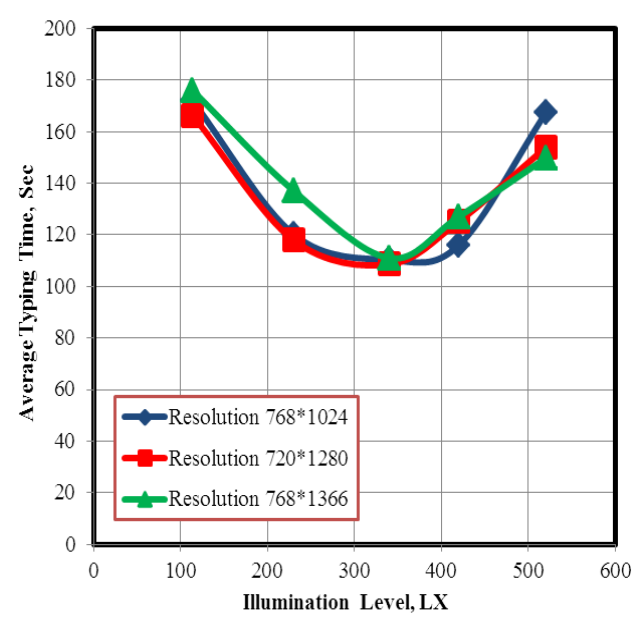

Fig. 7 Interaction plot between illumination level and average typing time at different screen resolution

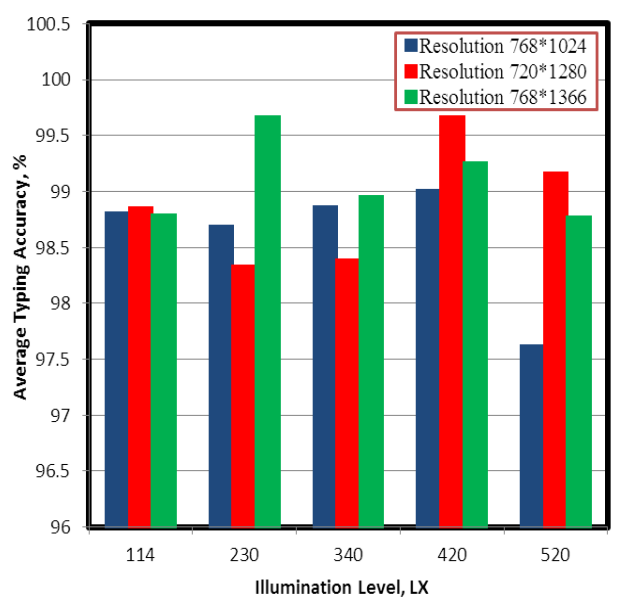

Fig. 8 Interaction plot between illumination level and average typing accuracy at different screen resolution 
Interaction plot between illumination level and average typing time at different zoom level, was shown in Fig. 9. It can be noticed that, no significant effect for screen resolution on average typing time. The same trend observed at all screen resolution with illumination level. The Interaction plot between illumination level and average typing accuracy at different zoom level was shown in Fig.10.

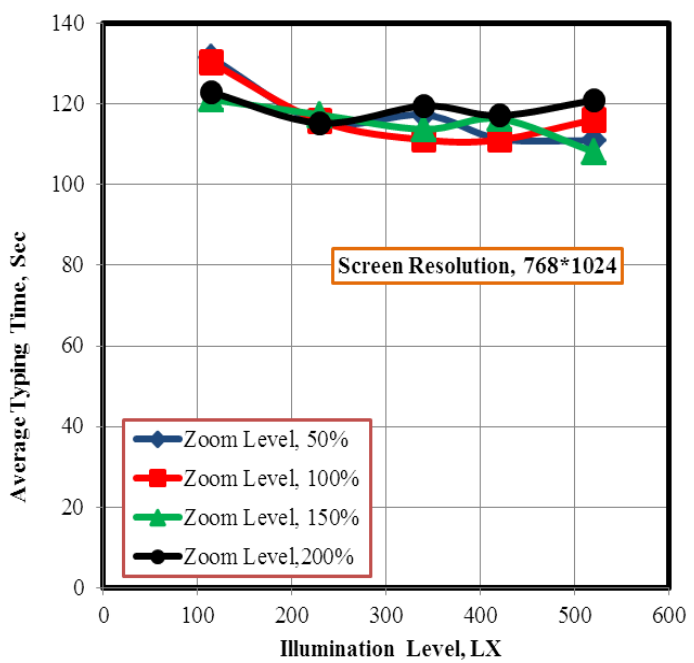

Fig. 9 Interaction plot between illumination level and average typing time at different zoom level

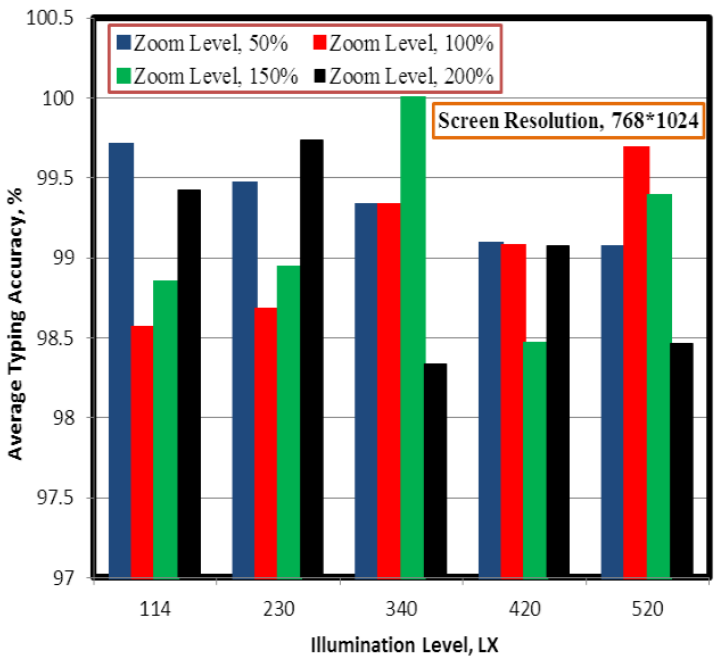

Fig. 10 Interaction plot between illumination level and average typing accuracy at different zoom level

Figure 11 show the Interaction plot between illumination level and average typing time at different zoom level. The minimum average typing time observed at 3401x illumination level at 100,150 and $200 \%$ zoom level. The average typing accuracy at zoom level and different illumination was shown in Fig. 12.

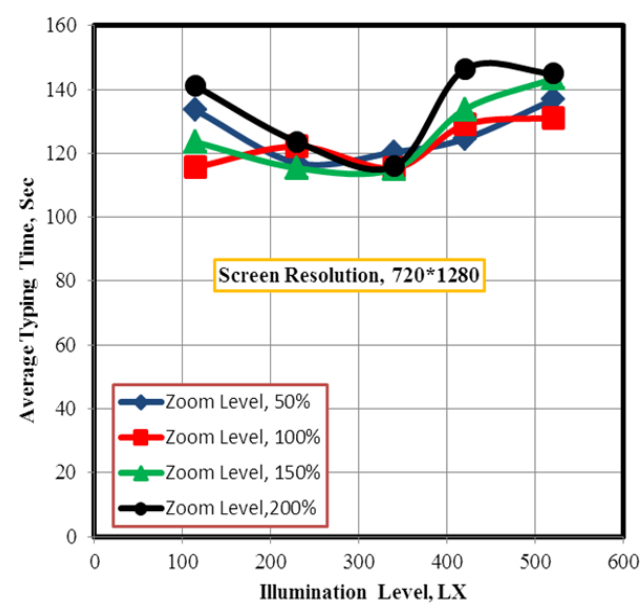

Fig. 11 Interaction plot between illumination level and average typing time at different zoom level

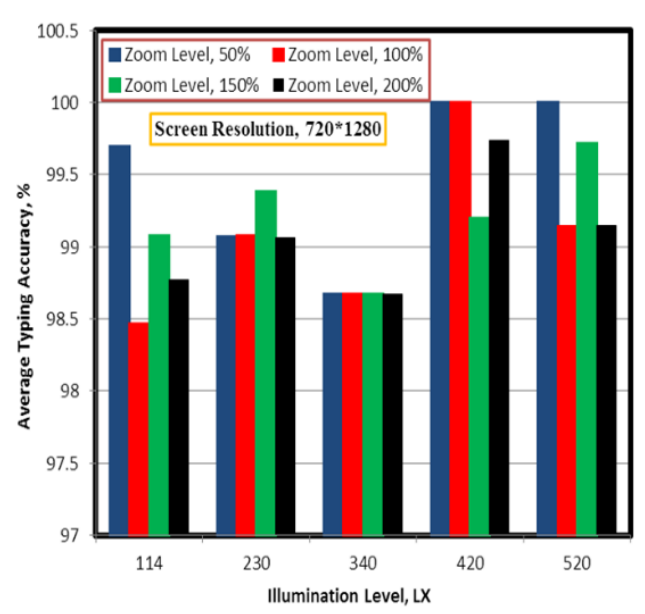

Fig. 12 Interaction plot between illumination level and average typing accuracy at different zoom level 
Interaction plot between illumination level and average typing time at different zoom level was shows in Fig. 11. The minimum average typing time observed at $150 \%$ zoom level followed by $100 \%$ zoom level. The average typing time slightly decrease with increasing illumination level up to 3401x. Figure 14 shows the Interaction plot between illumination level and average typing accuracy at different zoom level, the heights typing accuracy observed at 340lx illumination level and 100, 150\% zoom level.

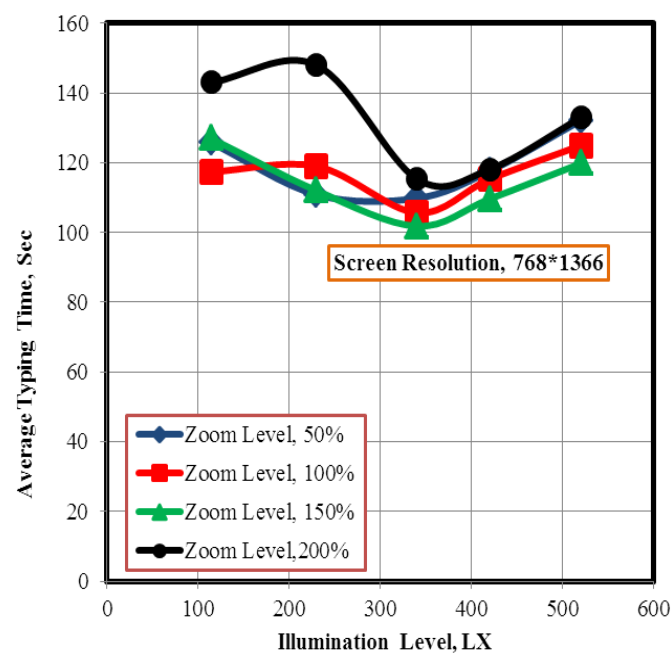

Fig. 13 Interaction plot between illumination level and average typing time at different zoom level

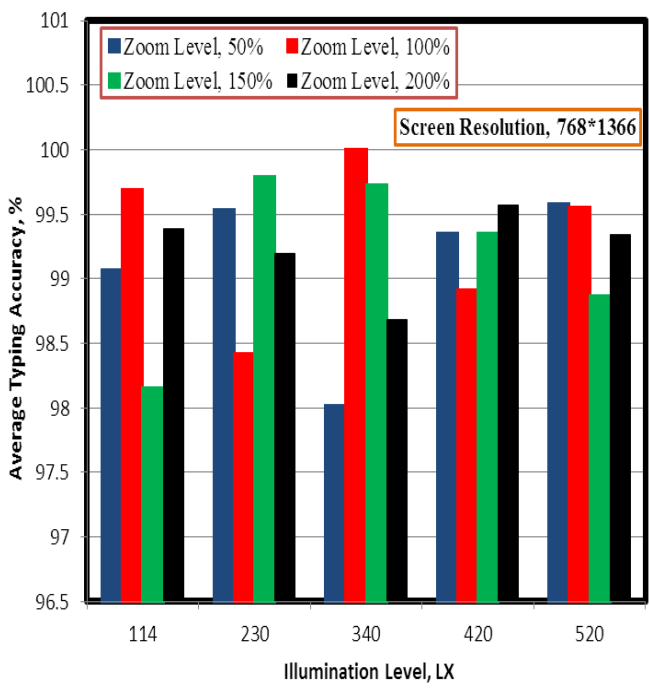

Fig. 14 Interaction plot between illumination level and average typing accuracy at different zoom level

The Analysis of variance (ANOVA) was use to estimate the significance of each control factor effect on the response factor, by calculating the contribution of each factor effect. The results of ANOVA illustrated graphically by Pareto chart. Plotting the Pareto chart for effects, gives a very good ideas about the relative importance of each effect, so any factor or interaction has an insignificant effect was eliminated from the chart, as well as, pooled to the error, and discarded from the prediction calculations.

Table 7. show the parameters definitions:

\begin{tabular}{|c|c|c|c|c|c|}
\hline \multicolumn{2}{|c|}{ A } & \multicolumn{2}{c|}{ B } & \multicolumn{2}{c|}{ C } \\
\hline \multicolumn{2}{|c|}{ ILLUMINATION } & SCREEN RESOLUTION & \multicolumn{2}{c|}{ ZOOM LEVEL } \\
\hline LEVEL 1 & 114 LX & LEVEL 1 & $768 * 1024$ & LEVEL 1 & $50 \%$ \\
\hline LEVEL 2 & $230 \mathrm{LX}$ & LEVEL 2 & $720 * 1280$ & LEVEL 2 & $100 \%$ \\
\hline LEVEL 3 & $340 \mathrm{LX}$ & LEVEL 3 & $768 * 1366$ & LEVEL 3 & $150 \%$ \\
\hline
\end{tabular}

Based on S/N Ratio the optimum parameters was 1A, 1B and $1 \mathrm{C}$, this parameters is $114 \mathrm{~lx}$ illumination level and 768*1024 screen Resolution and 50\% zoom level. Based on standard deviation the optimum parameters was $1 \mathrm{~A}, 3 \mathrm{~B}$ and $3 \mathrm{C}$, this parameters is $114 \mathrm{~lx}$ illumination level and $768 * 1366$ screen Resolution and $150 \%$ zoom level. Based on the means the optimum 
parameters was $2 \mathrm{~A}, 3 \mathrm{~B}$ and $2 \mathrm{C}$, this parameters is $2301 \mathrm{x}$ illumination level and $768 * 1366$ screen Resolution and $100 \%$ zoom level.
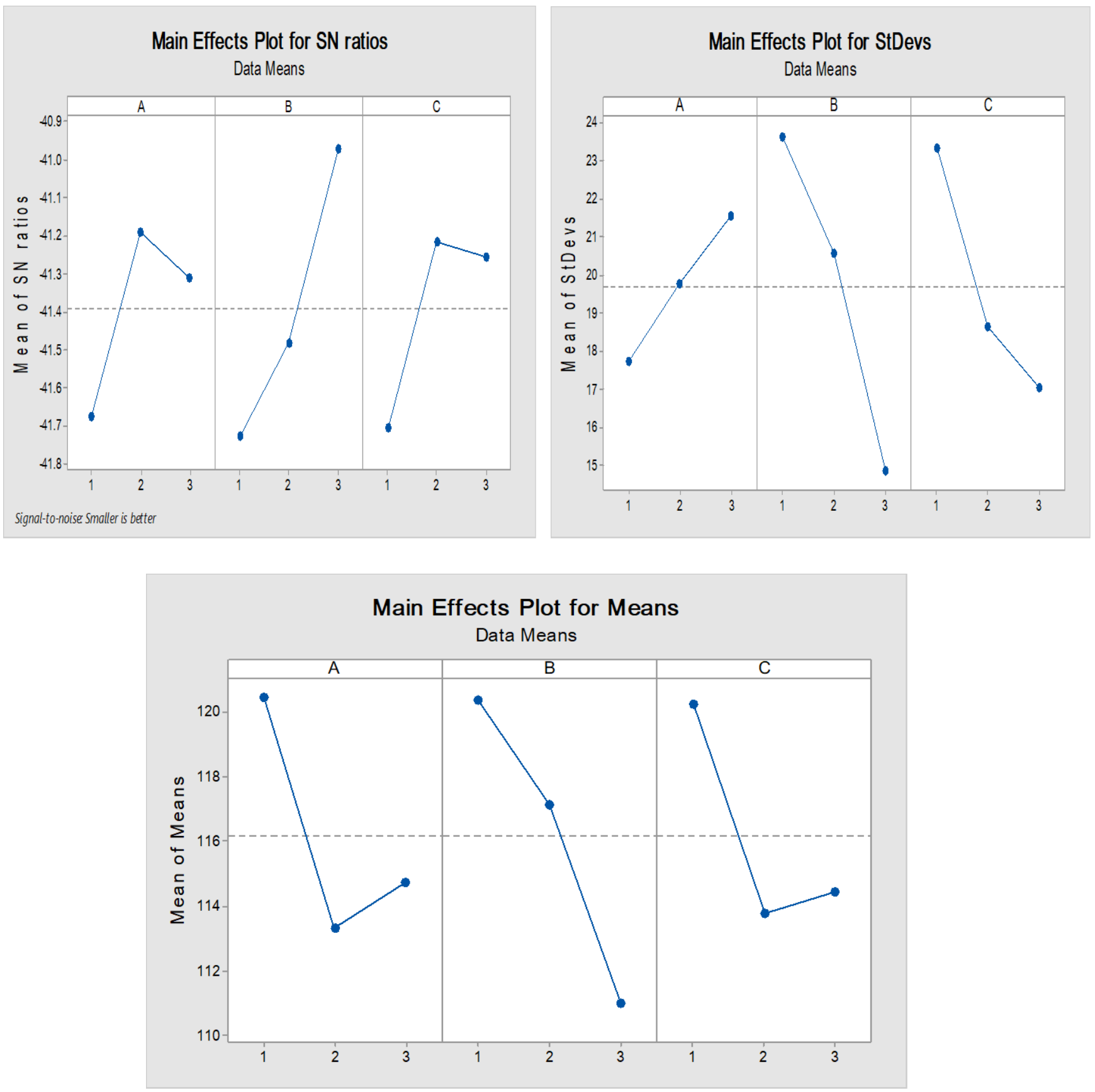

\section{Response Table for Signal to Noise Ratios, Smaller is better.}

The response table show the most influencing parameters effect on average typing time. The response table for $\mathrm{S} / \mathrm{N}$ ratio shown the screen resolution is the most influencing parameters then the scale level and the last illumination level. The response table for the means shown the screen resolution is the most influencing parameters then the illumination level and the final scale level. The response table for standard deviation shown the screen resolution is the most influencing parameters then the scale level and the last illumination level. 
Table 8. Response Table for $\mathrm{S} / \mathrm{N}$ ratio.

\begin{tabular}{|c|c|c|c|}
\hline Level & ILLUMINATION & $\begin{array}{c}\text { SCREEN } \\
\text { RESOLUTION }\end{array}$ & $\begin{array}{c}\text { ZOOM } \\
\text { LEVEL }\end{array}$ \\
\hline 1 & -41.68 & -41.73 & -41.71 \\
\hline 2 & -41.19 & -41.48 & -41.22 \\
\hline 3 & -41.31 & -40.97 & -41.25 \\
\hline Delta & 0.49 & 0.76 & 0.49 \\
\hline Rank & 3 & 1 & 2 \\
\hline
\end{tabular}

Table 9. Response Table for Means

\begin{tabular}{|c|c|c|c|}
\hline Level & ILLUMINATION & $\begin{array}{c}\text { SCREEN } \\
\text { RESOLUTION }\end{array}$ & $\begin{array}{c}\text { ZOOM } \\
\text { LEVEL }\end{array}$ \\
\hline 1 & 120.5 & 120.4 & 120.3 \\
\hline 2 & 113.3 & 117.1 & 113.8 \\
\hline 3 & 114.7 & 111 & 114.5 \\
\hline Delta & 7.1 & 9.4 & 6.5 \\
\hline Rank & 2 & 1 & 3 \\
\hline
\end{tabular}

Table 10. Response Table for Standard Deviations

\begin{tabular}{|c|c|c|c|}
\hline Level & ILLUMINATION & $\begin{array}{c}\text { SCREEN } \\
\text { RESOLUTION }\end{array}$ & $\begin{array}{c}\text { ZOOM } \\
\text { LEVEL }\end{array}$ \\
\hline 1 & 17.75 & 23.62 & 23.35 \\
\hline 2 & 19.76 & 20.57 & 18.65 \\
\hline 3 & 21.56 & 14.88 & 17.06 \\
\hline Delta & 3.81 & 8.75 & 6.29 \\
\hline Rank & 3 & 1 & 2 \\
\hline
\end{tabular}

The analysis of variance (ANOVA) and of mean (ANOM), standard deviation of the observed raw data, and $\mathrm{S} / \mathrm{N}$ ratio as lowest the better was carried to identify the significant variables and to quantify their effects on the response characteristics.

Table 11. Analysis of Variance $\mathrm{S} / \mathrm{N}$ ratio (ANOVA)

\begin{tabular}{|c|c|c|c|c|c|}
\hline Source & DF & Adj SS & $\begin{array}{c}\text { Adj } \\
\text { MS }\end{array}$ & $\begin{array}{c}\text { F- } \\
\text { Value }\end{array}$ & $\begin{array}{c}\text { P- } \\
\text { Value }\end{array}$ \\
\hline ILLUMINATION & 2 & 0.3882 & 0.1941 & 1.07 & 0.0484 \\
\hline $\begin{array}{c}\text { SCREEN } \\
\text { RESOLUTION }\end{array}$ & 2 & 0.8949 & 0.4475 & 2.46 & 0.0289 \\
\hline ZOOM LEVEL & 2 & 0.448 & 0.224 & 1.23 & 0.0448 \\
\hline Error & 2 & 0.3635 & 0.1818 & & \\
\hline
\end{tabular}




\begin{tabular}{|c|c|c|l|l|l|}
\hline Total & 8 & 2.0946 & & & \\
\hline
\end{tabular}

Table 12. Analysis of Variance Mean (ANOM)

\begin{tabular}{|c|c|c|c|c|c|}
\hline Source & DF & Adj SS & $\begin{array}{c}\text { Adj } \\
\text { MS }\end{array}$ & $\begin{array}{c}\text { F- } \\
\text { Value }\end{array}$ & $\begin{array}{c}\text { P- } \\
\text { Value }\end{array}$ \\
\hline ILLUMINATION & 2 & 85.72 & 42.86 & 1.41 & 0.0414 \\
\hline $\begin{array}{c}\text { SCREEN } \\
\text { RESOLUTION }\end{array}$ & 2 & 136.65 & 68.32 & 2.25 & 0.0307 \\
\hline ZOOM LEVEL & 2 & 75.9 & 37.95 & 1.25 & 0.0444 \\
\hline Error & 2 & 60.65 & 30.32 & & \\
\hline Total & 8 & 358.92 & & & \\
\hline
\end{tabular}

Table 13. Analysis of Variance Standard deviation (ANOVA)

\begin{tabular}{|c|c|c|c|c|c|}
\hline Source & DF & Adj SS & $\begin{array}{c}\text { Adj } \\
\text { MS }\end{array}$ & $\begin{array}{c}\text { F- } \\
\text { Value }\end{array}$ & $\begin{array}{c}\text { P- } \\
\text { Value }\end{array}$ \\
\hline ILLUMINATION & 2 & 21.83 & 10.92 & 0.68 & 0.0594 \\
\hline $\begin{array}{c}\text { SCREEN } \\
\text { RESOLUTION }\end{array}$ & 2 & 118.3 & 59.15 & 3.7 & 0.0213 \\
\hline ZOOM LEVEL & 2 & 64.23 & 32.11 & 2.01 & 0.0332 \\
\hline Error & 2 & 31.95 & 15.98 & & \\
\hline Total & 8 & 236.32 & & & \\
\hline
\end{tabular}

Residual plots are used to evaluate the data for the problems like non normality, non-random variation, non-constant variance, higher-order relationships, and outliers.

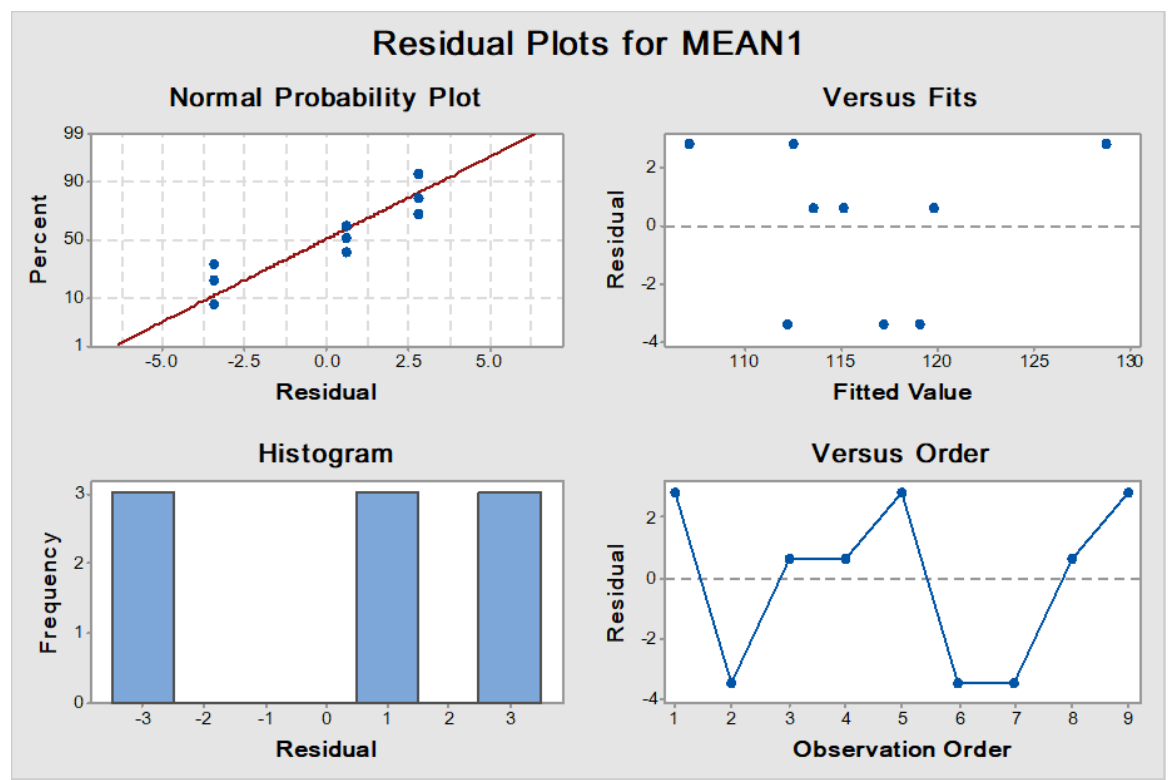



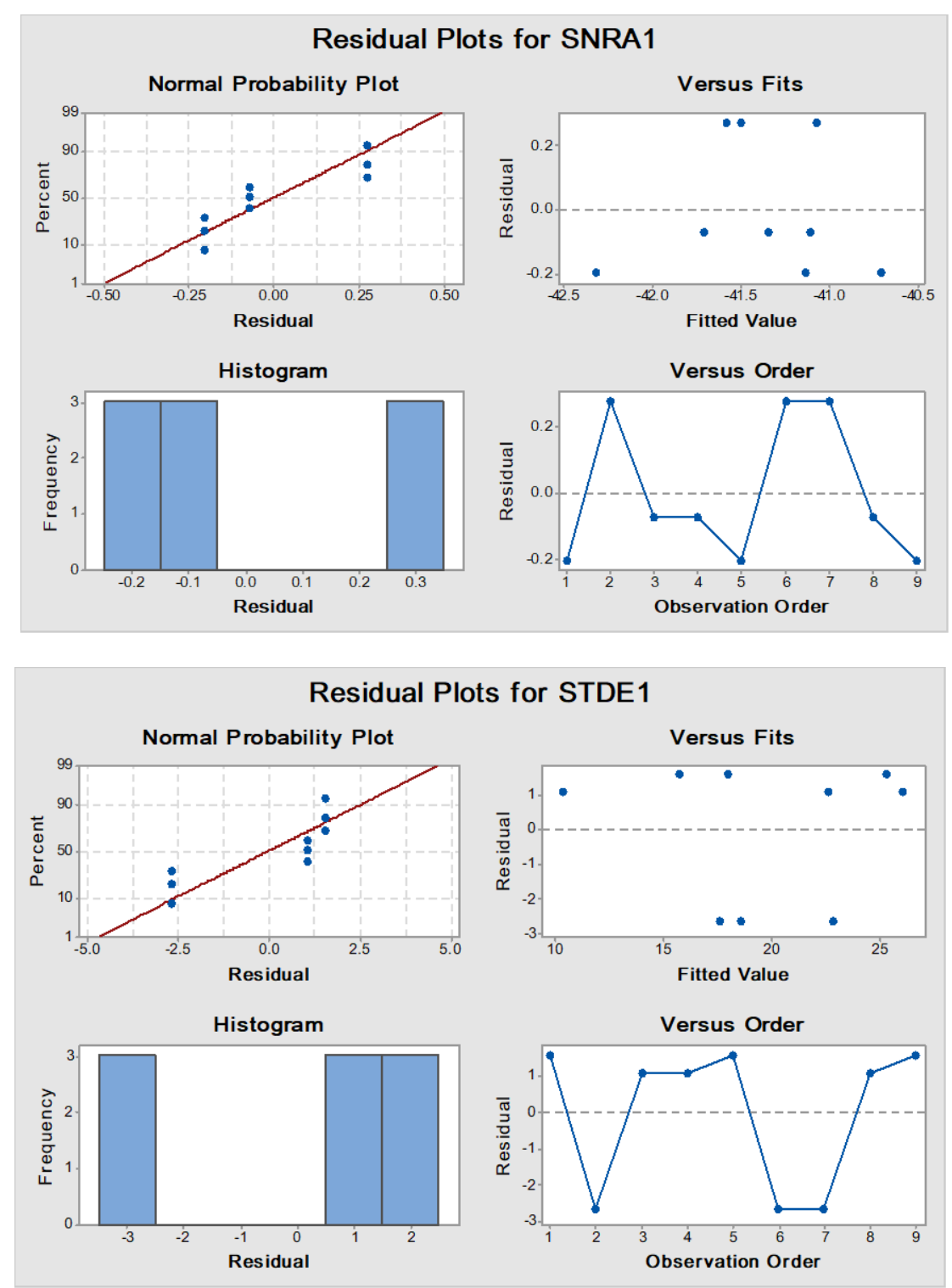

\section{CONCLUSIONS:}

The more effective illumination level on average typing time was 340 followed by $420 \mathrm{~lx}$. Average typing time decrease with increasing screen resolution, the minimum average typing time observed at $720 * 1280$ and $168 * 1366$ screen resolution. Change the zoom level of text show significant effect on typing time, which the average typing time decreases with increasing zoom level. The minimum typing time observed at 100 and $150 \%$ zoom level. Experimental results for all $\mathrm{S} / \mathrm{N}$ ratio, mean, and standard deviation (real) response values show that, illumination level, screen resolution and zoom scale are the significant parameters among all controllable factors that influence the avearge typing time. Based on S/N Ratio the optimum parameters was 114 lx illumination level and 768*1024 screen Resolution and 50\% zoom level. Based on standard deviation the optimum parameters was 114 lx illumination level and $768 * 1366$ screen Resolution and $150 \%$ zoom level. Based on the means the optimum parameters was is $2301 x$ illumination level and $768^{*} 1366$ screen resolution and $100 \%$ zoom level. 


\section{ACKNOWLEDGEMENTS:}

The authors would like to thank the Deanship of Scientific Research at Jazan University for supporting this work.

\section{REFERANCES:}

1. Ministerial regulation, Standards for the management of safety, ealth and environment about heat, light and sound, 2006.

2. C. C. Lin and C. K Huang, "Effects of ambient illumination conditions and background color on visual performance with TFTLCD screens," Displays,Vol.34, pp.276-282, 2013.

3. A.Uetake, A.Murata, M.Otsuka, and Y.Takasawa, "Evaluation of Visual Fatigue during VDT Tasks," presented at the 2000 IEEE Int.Conf. On Systems, Man \& Cybernatics, Nashville, TN.

4. ISO 8995-1: 2002 (E), Lighting of work places Part 1;Indoor, 2002

5. J.Anshel. Visual Ergonomics Handbook. Boca Raton,FL : CRC Press Taylor and Francis Group, 2005.pp.45-54.E. H. Miller, "A note on reflector arrays (Periodical style-Accepted for publication)," Engineering Letters, to be published.

6. Burke, R. The third wave of marketing intelligence. In: Krafft, M., Mantrala, M. (Eds.), Retailing in the 21st Century, pp. 113e125, 2006

7. Cushman, W.H., 1986. Reading from microfiche, a VDT, and the printed page: subjective fatigue and performance. Hum. Factors J. Hum. Factors Ergonomics Soc. 28 (1), $63 \mathrm{e} 73$. http://doi.org/10.1177/001872088602800107.

8. W. Hu, S. Tang, Z. Zhu, Modern Color Science and Application, Beijing Institute of Technology Press, 2007.

9. J. Shi, Problems in the application of CIECAM02 color appearance model and the methods to solve the problems, Laser Optoelectron. Prog. p.p 418-25, (2011).

10. Z. Lu, Z. Liu, J. Zhang, Simple - contrast of ambient light and just noticeable lightness threshold model, Acta Opt. Sin. 4, (2014).

11. S.Y. Choi, M.R. Luo, M.R. Pointer, et al., Changes in colour appearance of a large display in various surround ambient conditions, Color Res. Appl. 35, p.p (3200-212), (2010).

12. Y.S. Baek, Y. Kwak, S. Park, et al. Monitor Brightness Perception Changes under Various Surround Condition (5), 39-43,(2013).

13. J.S. Laine, Adapting softcopy color reproduction to ambient illumination, J. Soc. Inf. Display vol. 11, (no. 2), p.p 359-369, (2012).

14. J.A. Brennan, P. Brennan, T.M. Haygood, Ambient Lighting in the Reading Room: Theoretical Concepts and Practical Outcomes, Curr. Med. Imaging Rev. 6 (3), p.p 156-164,(2015).

15. C.C. Lin, K.C. Huang, Displays, Effects of ambient illumination conditions and background color on visual performance with TFT-LCD screens, Int. J. Indus. Ergon. 34 (4), p.p 276-282,(2013).

16. R. Gong, H. Xu, Q. Wang, Z. Wang, H. Li, Investigation of perceptual attributes for mobile display image quality, Opt. Eng. 52 (8), 3104, (2013).

17. ISO/TC 159/SC 4 Ergonomics of human-system interaction, Ergonomic Requirements for Office Work With Visual Display Terminals (VDTs): Guidance on Usability, International Organization for Standardization, 1998.

18. G.F. Reed, F. Lynn, B.D. Meade, Use of Coefficient of Variation in Assessing Variability of Quantitative Assays, Clin. Diagn. Lab. Immunol. 9 (6), p.p 1235-1239, (2002).

19. P.G. Engeldrum, Psychometric Scaling: a Toolkit for Imaging Systems Development, Imcotek press, 2000.

20. Y.S. Baek, H.S. Kim, S. Park, Determination of the Perceived Contrast Compensation Ratio for a Wide Range of Surround Luminance, J. Opt. Soc. Korea 18 (1), p.p 89-94,(2014). 
21. Zhaojing Xu, Qing Wang, , Rui Gong. "Effects of high ambient illuminations on image quality in mobile displays", Optik - International Journal for Light and Electron Optics 221 (2020) 164676, (2020).

22. Irén Juhász junger, Daniel Werner, Eva Schwenzfeier-Hellkamp, Andrea Ehrmann,“ Influence of illumination spectra on DSSC performance", Optik - International Journal for Light and Electron Optics 177 (2019) 8-12, (2019).

23. Sina Esteky, David B. Wooten, Maarten W. Bos, "Illuminating illumination: Understanding the influence of ambient lighting on prosocial behaviors", Journal of Environmental Psychology 68 (2020) 101405, (2020). 